\title{
Construction and Development of an Automated Greenhouse System Using Arduino Uno
}

\author{
T. Saha, M. K. H. Jewel, M. N. Mostakim, N. H. Bhuiyan, M. S. Ali and M. K. Rahman \\ Dept. of Applied Physics, Electronics \& Communication Engineering, Islamic university, Kushtia, Bangladesh \\ H. K. Ghosh and Md. Khalid Hossain* \\ Institute of Electronics, Atomic Energy Research Establishment, Savar, Dhaka-1349, Bangladesh \\ *Corresponding Author Email: khalid.baec@yahoo.com
}

\begin{abstract}
An automated greenhouse is a framework that utilizes nursery innovations to make a positive ecological condition virtually to develop ideal creation of plants. Controlling climatic conditions are one of the most critical challenges in agribusiness. In like manner, a robotized nursery framework has been developed to accomplish observations and controlling of the climatic parameters which is straightforwardly or in a roundabout way that administers the plants development and generation. In a nursery using greenhouse structure that is made with glass or plastic it warms up from approaching obvious sun oriented radiation which is consumed by the plants and absorbed by the surface. Eventually air is warmed by the warmth from hot inside surfaces and held within the nursery dividers that makes the environment inside it warmer. With the association of present day innovations, this research takes a risk to actualize these frameworks for farming with no human consideration. The motivation behind this exploration is to make an innovation that makes exceedingly exact environment in a work sparing angle. In this work an Atmega328 MCU is utilized to do some predefined tasks, made by some specific codes with the help of an Arduino prototyping board. The system projects the parameters in a display as well as controls four vital parameters like temperature, light, humidity and soil moisture to accomplish viability and functionality of nursery environment control gadgets.
\end{abstract}

Index Terms - Greenhouse, Humidity, Moisture, Sensor, AT-MEGA328, Light Dependent Resistor.

\section{INTRODUCTION}

Greenhouse is an important part in agriculture and horticulture sectors. It can be used to grow plants under controlled climatic conditions for optimum production. Crop production and quality have significantly increased with the utilization of greenhouse which has helped us to cope with the ongoing rising demands.

For the improvement of greenhouse technology, the first attempt was made to develop automated system for watering plants [1]. To achieve the better enhancement of the growth of the plants in greenhouse, Data Acquisition Using Arduino was introduced [2]. For improving the performance of greenhouse automation, microcontroller
(Keil Compiler based 8051) with A/D converter is used [3]. The climatic condition which is favorable for the mini Orchid was studied. According to the study, finally mini Orchid Greenhouse was designed successfully that was automated [4].

Now a day's agriculture doesn't only limit to cultivate crops rather following convenient and efficient way to grow more crops. The demand \& usefulness of greenhouse technology is increasing with increase in population and there is no alternative of it to cope with epicurean lifestyles of people. Not only that, it is not convenient to rely on natural climatic condition in agriculture. It can easily be realized from the histories behind the development of greenhouse technology. In 30 $\mathrm{AD}$ at Rome; the ailing emperor Tiberius once became sick and was asked by the royal physician to take cucumber as medicine. But the season wasn't favorable enough to get cucumber. Eventually a room with transparent roof was made. Sunlight used to be passed through the transparent roof and additional heat could have been given into it from outside from a fireplace to maintain optimum warmth. That was how greenhouse had been invented [5].

The objective of this work is to design a simple, easy to install, microcontroller-based circuit to monitor and record the values of temperature, humidity, soil moisture and sunlight of the natural environment that are continuously modified and controlled in order to optimize them to achieve maximum plant growth and yield. This makes the proposed system to be an economical, portable and a low maintenance solution for greenhouse applications, especially in rural areas and for small scale agriculturists.

The rest of the paper has been designed as followssection-2 proposed system, section-3 hardware design and development, section-4 system simulation, results \& discussion and discussion and section- 5 conclusions.

\section{RELATED WORK}

To manage greenhouse with the Embedded System and Zigbee Technology was implemented by S.Thenmozhi et al [6]. Remote Monitoring Station was implemented by Jonathan A. Enokela et al [7] for securing Greenhouse Control System. Climate monitoring system based on 
Wireless Sensor Network (WSN) technology was developed by Mahmoud Shakeret et al [8]. A. Rahali et al [9] developed greenhouse system based on GSM. CAN Bus is used to automate green house by Shridhar Joteppagol.M et al [10]. By using ARM7 Controller Sushama Arjun Kolhe et al [11] describe greenhouse automation. Another technique was implemented by using Zigbee and Smart Phone. Y.R.Dhumal et al [12] had implemented this by using synchronizing software (TEAM VIEWER) to communicate with Visual Basic Software via Web Server to an Android mobile phone. The natural and the artificial environments are combined by R.Arunraj et al [13]. In this system temporarily opened/closed roof is used to utilize natural heat for the purpose of maintain room temperature. This system also uses PLC technology that controls multiple environments at a time.

\section{PROPOSED SYSTEM}

This system consists of various sensors, namely soil moisture, temperature, humidity and light sensors. These sensors sense various parameters and are then sent to the microcontroller. Here, Atmega328 MCU is used which controls the greenhouse.

To implement greenhouse environment, soil moisture sensors, temperature sensors, LDR, humidity sensors are studied. After studying these, the program has been written on to the microcontroller for specific environment conditioning.

The desired temperature and humidity are maintained by turning on heater/cooler. The moisture level within soil is also be controlled by turning the water valve on/off. Desired light intensity for that environment can also be controlled by emergency lights when necessary. Hence, the greenhouses' environment is controlled automatically.

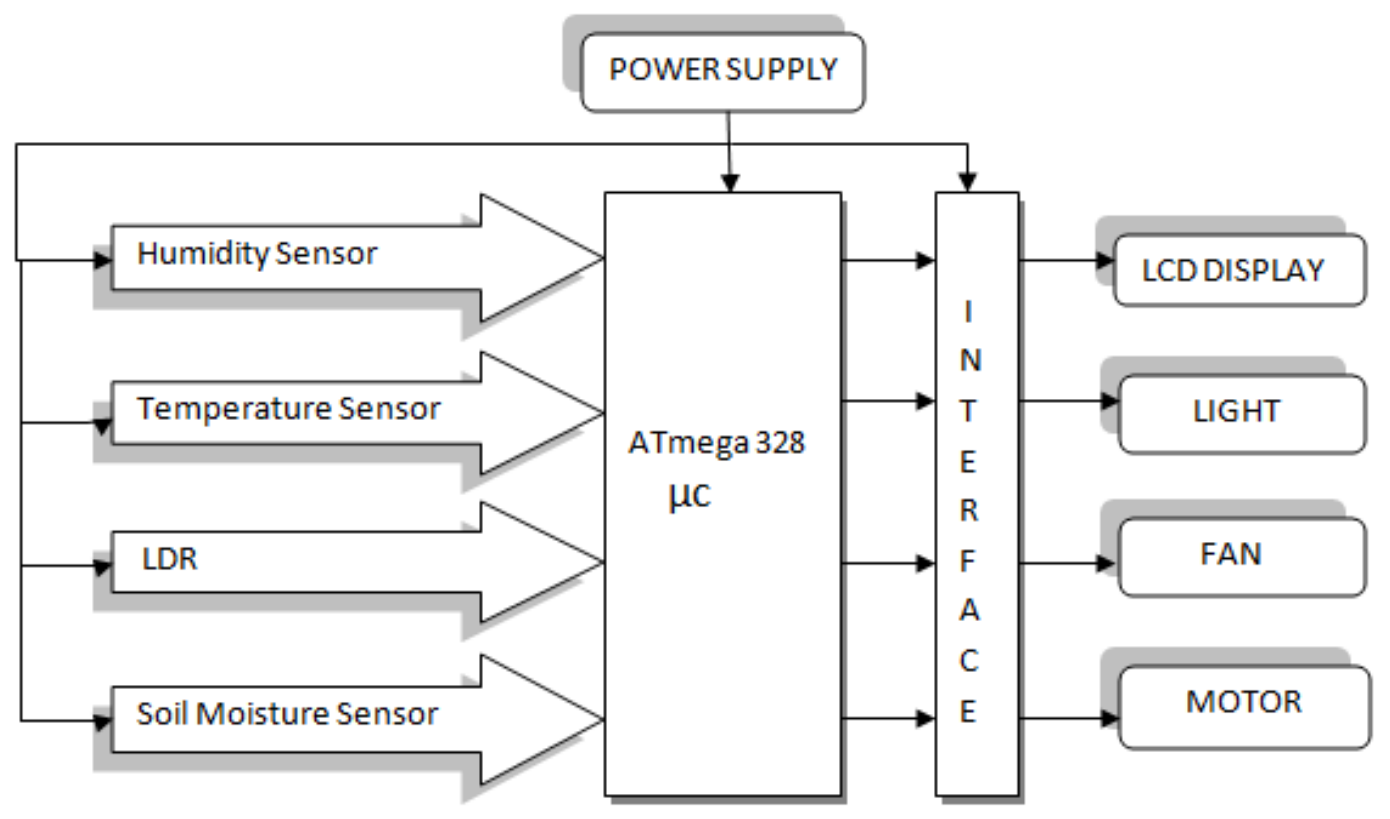

Fig.1. Block Diagram of the Proposed System

Fig.1 illustrates a block diagram of greenhouse automation system design with its hard ware components involved and connections. Here the main component is the microcontroller (At mega 328). Four sensors have been used to feed the input parameters at AT mega 328. It reads this sensor output and can generate output according to the program written into it. It can read both digital and analog inputs and can generate digital output. For example, ATmega 328 reads analog data from humidity sensor and then generates digital high/low output according to the threshold value which is written in the program, if it reads digital data from the moisture sensor then it can generate digital high/low output according to the internal logic written into the program. The microcontroller constantly monitors the digitized parameters of the various sensors and verifies them with the predefined threshold values and checks if any corrective action is to be taken for the condition at that instant. In case if such a situation arises, it activates the actuators to perform a control operation. An array of actuators can be used in the system such as relays, contactors, and change over switches etc. They are used to turn on AC devices such as motors, coolers, pumps etc. For the purpose of demonstration relays have been used to drive AC bulbs to simulate actuators and AC devices. A complete working system can be realized by simply replacing these simulation devices by the actual devices. Implementation of the proposed system can be done in two ways:

1) As a research system: Any agriculture farm can evaluate system requirements for an individual plant species by setting different logics and values to get desired results.

2) As a product: This proposed system can be supplied as a package product with predefined climatic parameters required for different species. 


\section{HARDWARE DESIGN AND DEVELOPMENT}

Fig. 2 represent the graphical representation of the application of the system. The hardware system is developed with combination three different parts.

\section{A. Humidity\& Temperature Sensors}

Humidity is the presence of water in air. Therefore, to measures both moisture and air temperature, this part of the system monitors real time humidity and temperature data from the area continuously to keep the greenhouse humidity and temperature at desired level. The greenhouse system has some static humidity and temperature levels. Above/bellow those values, the microcontroller sends corresponding signal to the interface devices that turns on the air-condition on to restore the greenhouse humidity and temperature. It takes analog input from the humidity and temperature sensors and provides digital output. The flowcharts of the operations are shown in Fig. 3 and Fig. 4.

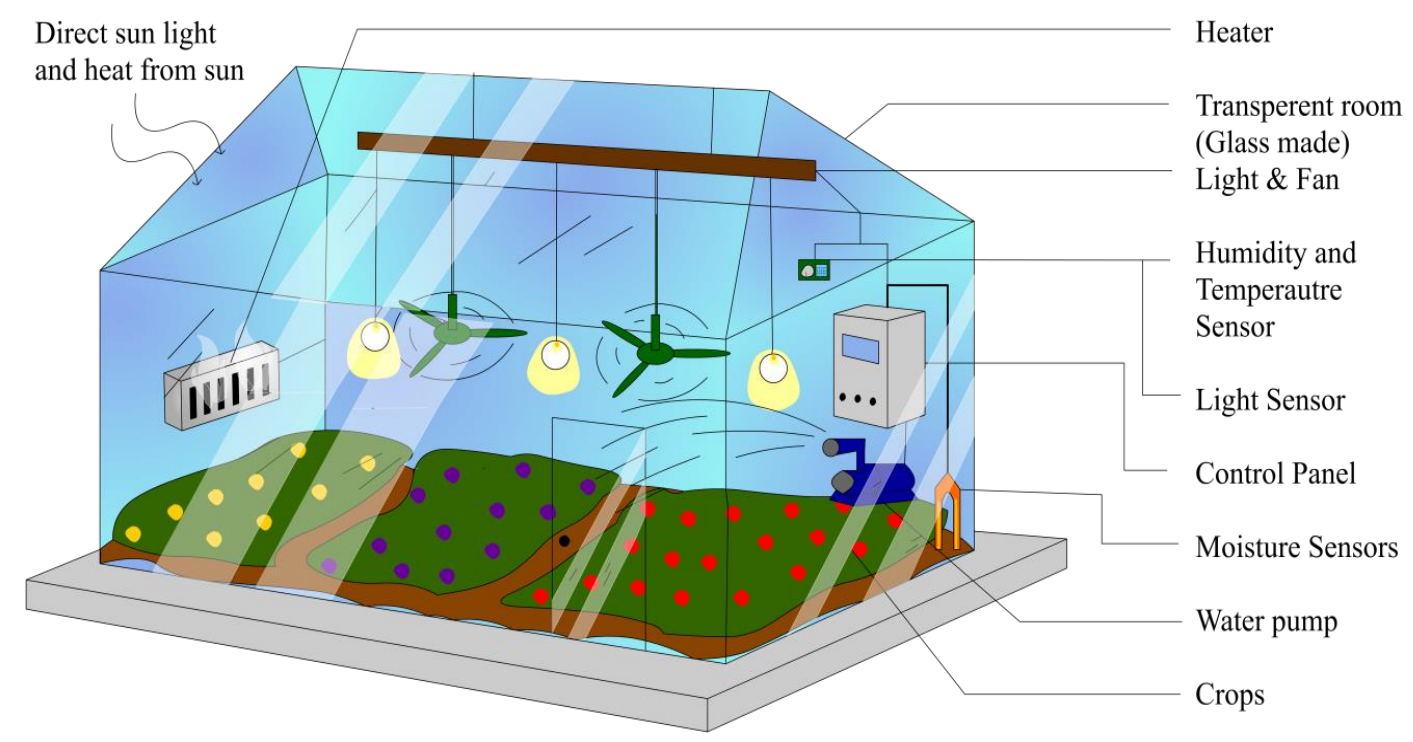

Fig.2. Graphical representation of the application of the system.

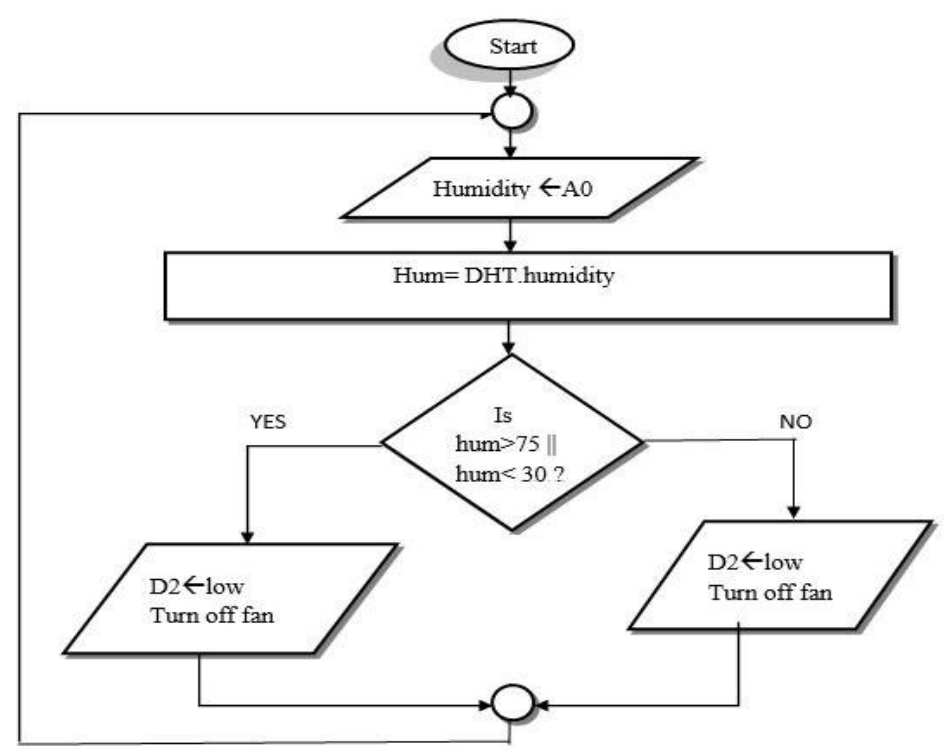

Fig.3. Flowchart for humidity measurement. 


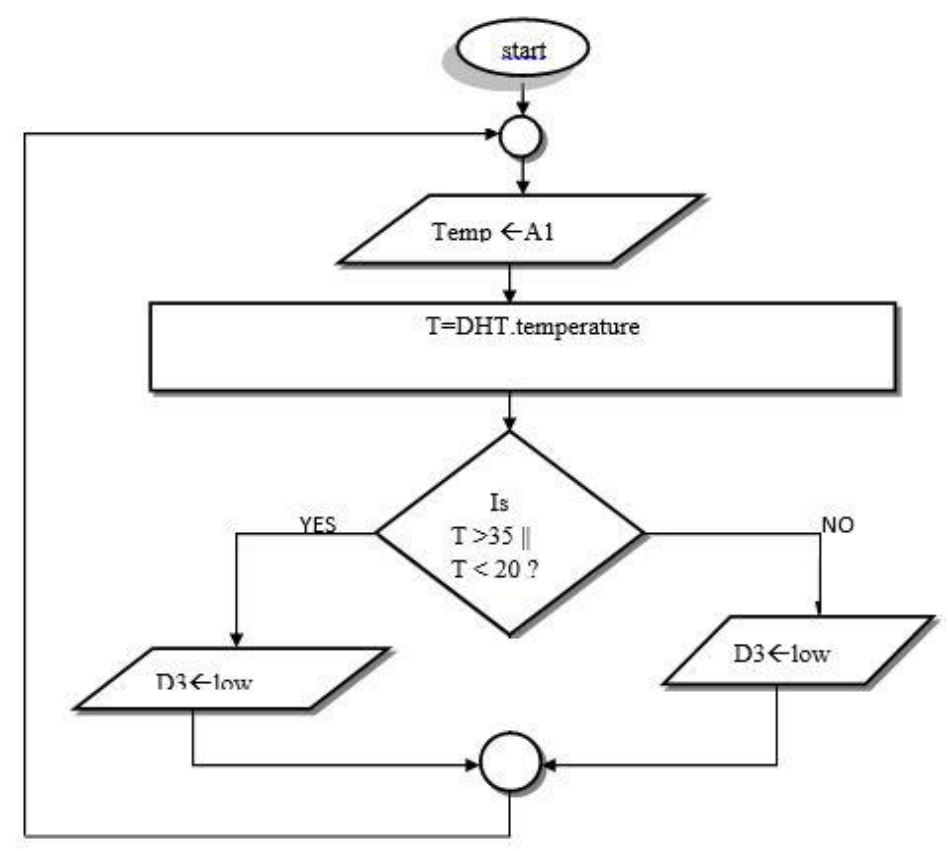

Fig.4. Flowchart for temperature measurement.

\section{B. Soil Moisture Sensors}

This section has been used to detect the water level in the corresponding greenhouse. If there is a lack of water in greenhouse the detector senses, it and sends signal to the microcontroller. Therefore, the microcontroller sends signal to the corresponding devices to turn on the pump. Furthermore, when the soil has moisture to a desired level the microcontroller sends signal to turn off the pump through interfacing devices according to the sensors output. The program is written on the microcontroller according to the flowchart represent in Fig. 5.

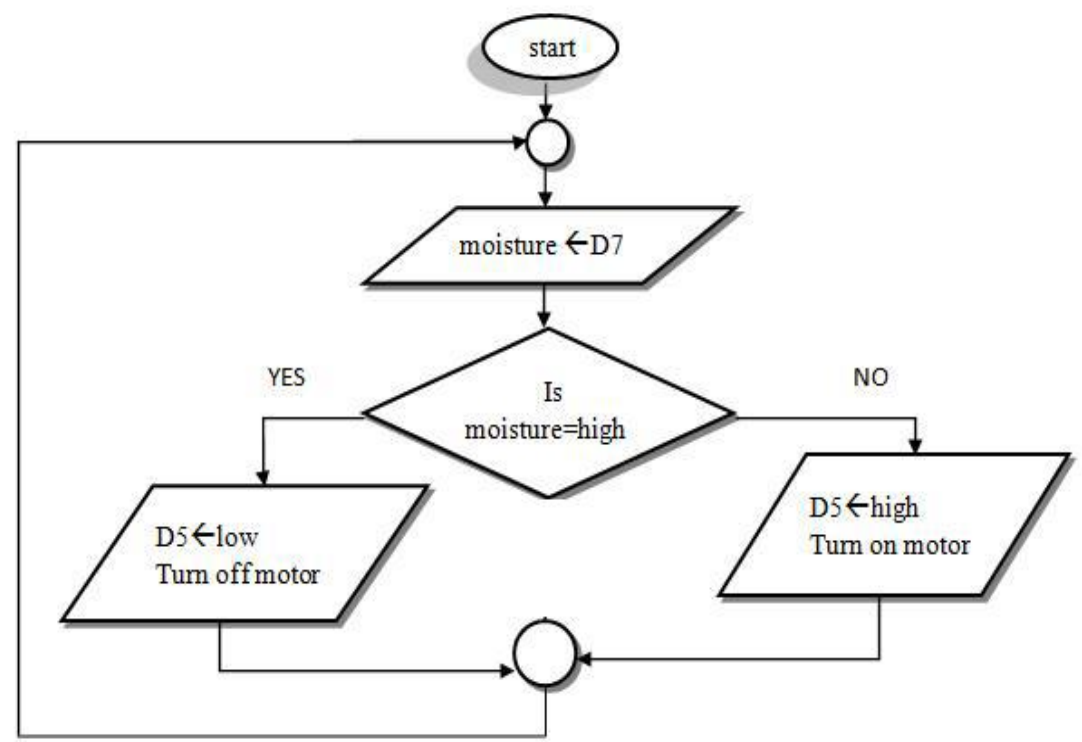

Fig.5. Flowchart for automatic water pump control.

\section{Light Dependent Resistor (LDR)}

If there is a lack of sunlight in greenhouse the detector senses, it and sends signal to the microcontroller. Therefore, the microcontroller sends corresponding signal to the interfacing device to turn on the lights.
Furthermore, when sunlight is at a desired level the microcontroller sends signal to turn off the lights according to the sensor output. To on/off the lights in the greenhouse depending on the sunlight intensity, the program was written on the microcontroller according to the flowchart shown in Fig. 6. 


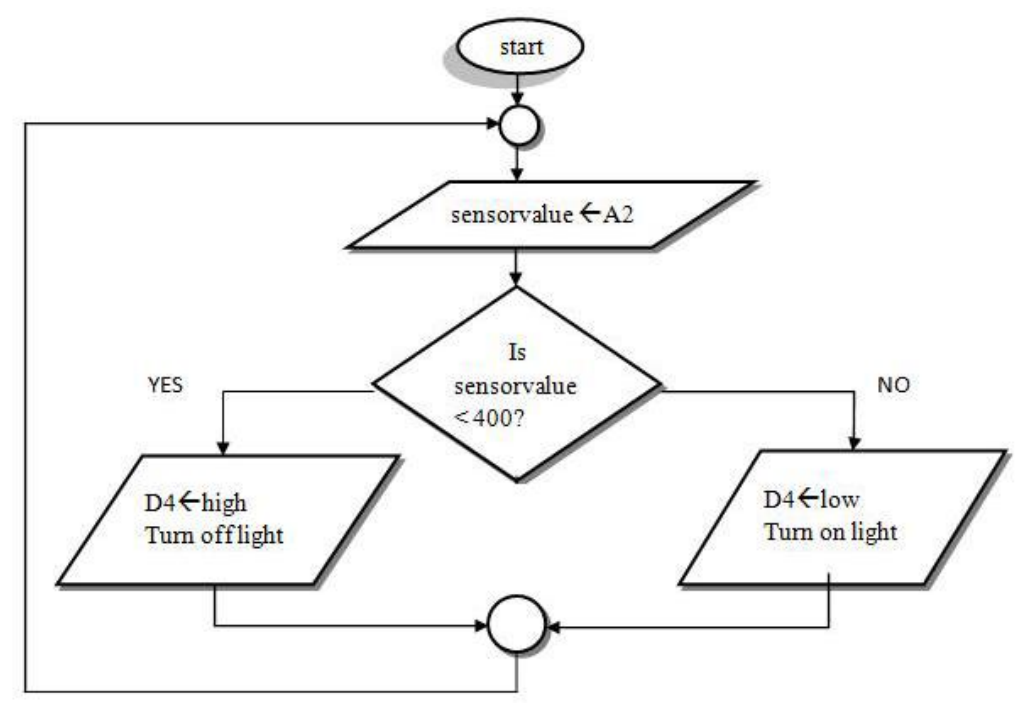

Fig.6. Flowchart for automatic light intensity control.

\section{SyStem Simulation, ResUlTS AND DisCUSSION}

The overall proposed automated greenhouse system containing temperature sensor, humidity sensor, LDR, soil moisture control system is simulated by using
Proteus 8 window, Table 1 illustrates system functions status for our project.

To maintain climatic condition inside the greenhouse the temperature, humidity, LDR and soil moisture sensors are used to sense the natural climatic condition, whose output signals used by the microcontroller to control the leading climate control devices shown in Fig. 7.

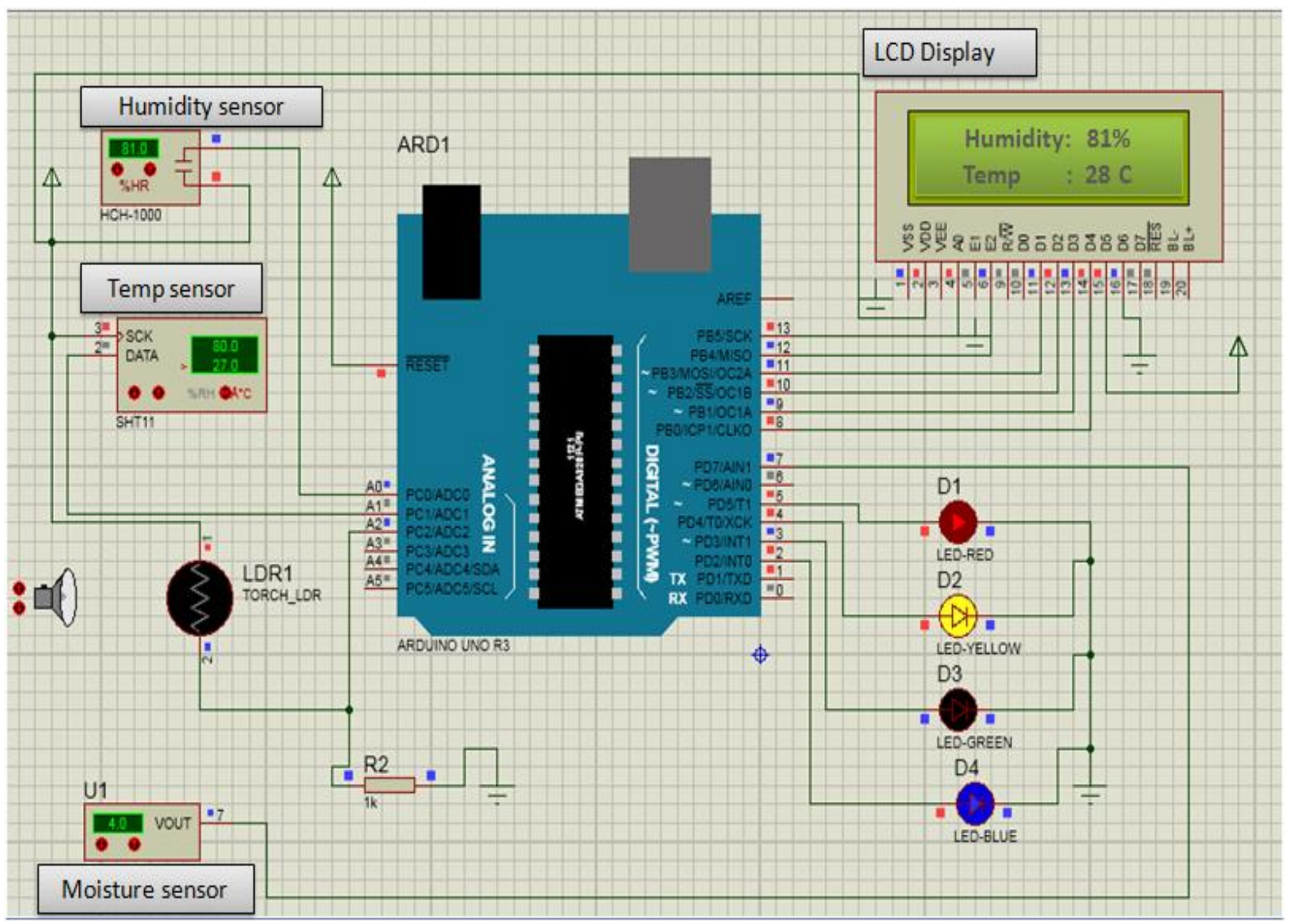

Fig.7. Simulation circuit of the system. 
Table 1. System functions status

\begin{tabular}{|c|c|c|c|c|c|c|c|c|}
\hline Obs no & $\begin{array}{c}\text { Hum } \\
\text { Value }\end{array}$ & $\begin{array}{c}\mu \mathrm{C} \\
\text { Action }\end{array}$ & $\begin{array}{c}\text { Temp } \\
\text { Value }\end{array}$ & $\begin{array}{c}\mu \mathrm{C} \\
\text { Action }\end{array}$ & $\begin{array}{c}\text { LDR } \\
\text { Value }\end{array}$ & $\begin{array}{c}\mu \mathrm{C} \\
\text { Action }\end{array}$ & Moisture Value & $\begin{array}{c}\mu \mathrm{C} \\
\text { Action }\end{array}$ \\
\hline 1 & $<30$ & High & $<20$ & High & $<400$ & High & High & Low \\
\hline 2 & $>75$ & High & $>35$ & High & $>400$ & Low & Low & High \\
\hline 3 & $>30 \&<75$ & Low & $>20 \&<35$ & Low & --- & --- & --- & \\
\hline
\end{tabular}

Climatic parameters such as humidity, temperature, light, soil moisture etc. have impact on agriculture. Starting from seed sow to crop collection every step has different requirements of climatic parameters. They even differ from species to species. So, to get optimum growth species wise it is necessary to ensure suitable temperature, humidity, light and soil moisture level. Table 2 represent the plant wise information of humidity and temperature level.

Table 2. Plant wise information of humidity and temperature level

\begin{tabular}{|c|c|c|c|c|}
\hline Obs no & Fruits & Suitable Country & Required Temperature & Required Humidity \\
\hline 1. & Watermelon & China, Turkey, Iran & Higher than about $25^{\circ} \mathrm{C}\left(77^{\circ} \mathrm{F}\right)$ to thrive & Medium \\
\hline 2. & Kiwifruit & China, Italy, New Zealand & Average Summer Heat & Average \\
\hline 3. & Strawberry & USA, Turkey, Spain & $15-27^{\circ} \mathrm{C}$ & Low \\
\hline 4. & Raspberry & Russia, Poland, United States & late summer and fall & High \\
\hline 5. & Orange & Brazil, United States, China, India & 15.5 and $29^{\circ} \mathrm{C}$ & Moderated \\
\hline
\end{tabular}

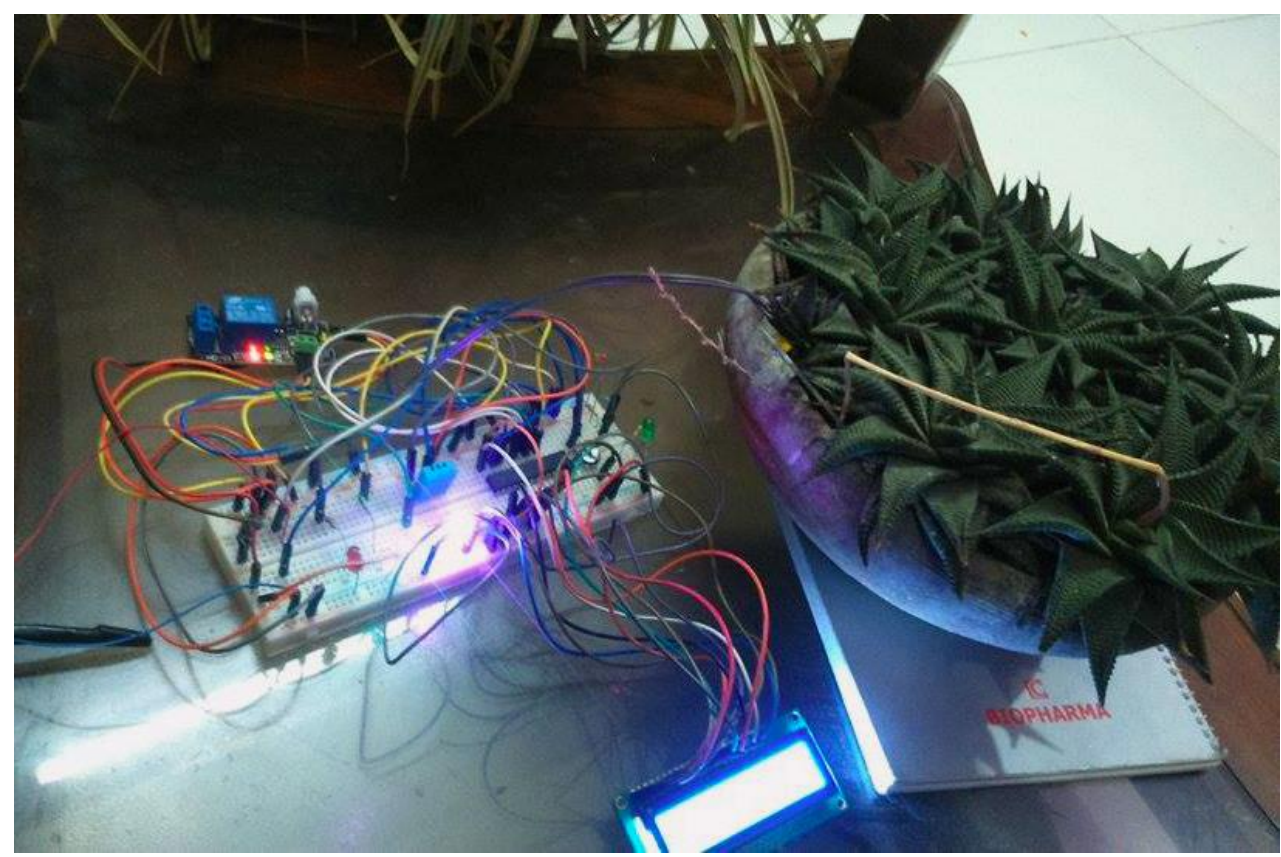

Fig.8. Implement circuit.

The Fig. 8 represent the practical implemented circuit of the developed system. Since the proposed system is a climate control package from the title there the climatic parameters are controlled automatically by using various sensors threshold values (programmable by microcontroller). In a greenhouse for good plantation some parameters like temperature, humidity, soil moisture and light must be controlled. For these reason four sensors (temperature sensor, humidity sensor, soil moisture sensor and LDR) are used to develop this system. The program is written on to the microcontroller for the specific environment conditioning. The desired temperature and humidity are maintained by turning on heater/cooler. The moisture in soil are also be controlled by turning the water valve on/off. The desired light flux for that environment can also be controlled by using emergency lights when necessary. Thus, the greenhouse environment is controlled automatically. The systems reaction time to restoration of variations of microclimatic parameters suffers from a few $\mu$ s delay because of the program scan cycle.

\section{CONCLUSIONS}

The developed system is suitable for both large scale agribusiness as well as small agriculture farm. For large scale agribusinesses, the cost will be increased for 
conditioning equipment's but the controlling cost will be same in all arenas which are significantly less than labor costs. Moreover, the efficiency and accuracy of the system is more accurate than manual systems. Human can observe whether the soil is wet or not. But the proposed system is able to measure the actual amount of moisture that is present in the soil. Again, it is very tough for human to measure actual light intensity, temperature and humidity while this proposed system can do them all very accurately. It eliminates risk of human errors to maintain a greenhouse at a specific environmental condition. Moreover, it is also eco-friendly. With the addition of wireless technologies between the sensors the system can be more reliable, cost effective for larger area and easy to implement. But this technology with wire connections is more suitable for small scale agribusinesses.

\section{REFERENCES}

[1] Devika SV, Khamuruddeen S, Khamurunnisa S, Thota J, Shaik K. Arduino Based Automatic Plant Watering System. International Journal of Advanced Research in Computer Science and Software Engineering. 2014 Oct; 4(10).

[2] Faris DM, Mahmood MB. Data acquisition of greenhouse using Arduino. Journal of Babylon University/Pure and Applied Sciences. 2014; 22(7):1908-6.

[3] Abdullah Tanveer, Abhishek Choudhary, Divya Pal, Rajani Gupta, Farooq Husain "Automated Farming Using Microcontroller And Sensors"; International Journal Of Scientific Research And Management Studies (IJSRMS) ISSN: 23493371 Volume 2 Issue 1, pg: 21-30.

[4] Ko CC, Mon SS. Microcontroller Based Greenhouse Automatic Control System. Int. J. Sci. Eng. Technol. Res. 2014; 3(5):0865-70.

[5] History of Greenhouse. [Online] Link: http://davesgarden.com/guides/articles/view/3607\#b

[6] Thenmozhi S, Dhivya MM, Sudharsan R, Nirmalakumari K. Greenhouse Management Using Embedded System and Zigbee Technology. International Journal of Advanced Research in Electrical, Electronics and Instrumentation Engineering. $2014 \mathrm{Feb}$; 3(2).

[7] Enokela JA, Othoigbe TO. An Automated Greenhouse Control System Using Arduino Prototyping Platform. Aust. J. Eng. Res.; 2(2).

[8] Shaker M, Imran AA. Greenhouse Micro Climate Monitoring Based On WSN with Smart Irrigation Technique. World Academy of Science, Engineering and Technology, International Journal of Electrical, Computer, Energetic, Electronic and Communication Engineering. 2013 Nov 3; 7(12):1566-71.

[9] Rahali A, Guerbaoui M, Ed-dahhak A, El Afou Y, Tannouche A, Lachhab A, Bouchikhi B. Development of a data acquisition and greenhouse control system based on GSM. International Journal of Engineering, Science and Technology. 2011; 3(8):297-306.

[10] Shridhar Joteppagol.M and Sheela. K. Kore "Greenhouse Automation Using CAN Bus"; International Journal For Research In Emerging Science And Technology, Volume2, Issue-5, May-2015.

[11] Kolhe SA, Annadate SA. Implementation of Green House Automation using ARM7 Controller. International Journal of Computer Applications. 2012 Jan 1; 47(20).

[12] Dhumal YR, Chitode JS. Green house automation using Zigbee and smart phone. International Journal of Advanced Research in Computer Science and Software Engineering Research Paper. 2013 May; 3(5).
[13] R.Arunraj , S.Motheeswaran, M.Venkatesan, M.Karthik, K.Raja "Smart Green House using PLC with Irrigation and Fertilizer Feeding"; IJSRD - International Journal for Scientific Research \& Development| Vol. 3, Issue 01, 2015 | ISSN (online): 2321-0613.

\section{Authors' Profiles}

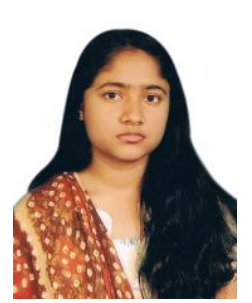

Tamosree Saha received her B.Sc. (Hons') degree from the dept. of Applied Physics, Electronics and Communication Engineering of Islamic University, Kushtia7003, Bangladesh in 2014. Currently she is a M.Sc. student in the same department. Her current interest includes microcontroller based system design, electronics system design and development, MATLAB based system development, MATLAB programming interface with microcontroller and communication engineering. She received University Merit Scholarship for her outstanding B.Sc. (Hons') $1^{\text {st }}$ class $2^{\text {st }}$ merit position out of 45 successful students from the authority of Islamic University, Bangladesh.

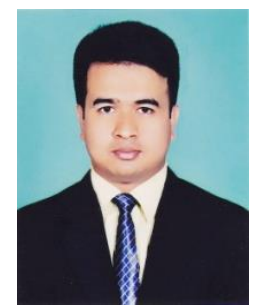

Md. Khalid Hossain Jewel received his Bachelor's and Master's degree from the dept. of Applied Physics, Electronics \& Communication Engineering of Islamic University, Kushtia-7003, Bangladesh in 2004 and 2005 respectively. In 2015 he completed his M.Phil degree in wireless communication. Currently he is working as an assistant professor in the same department. His research interest includes Ad-hoc wireless communication, intelligent systems design, cellular mobile communication and optical fiber communication.

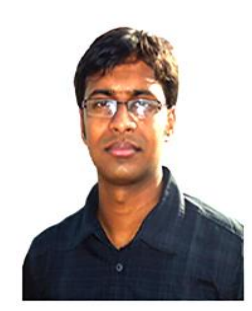

M. Niaz Mostakim received his B.Sc. (Hons') degree from the dept. of Applied Physics, Electronics and Communication Engineering of Islamic University, Kushtia-7003, Bangladesh in 2013. Currently he is a M.Sc. final year student in the same department. His current interest includes microcontroller based system design, electronics system design and development, MATLAB based system development, MATLAB programming interface with microcontroller and communication engineering. He received University Merit Scholarship for his outstanding B.Sc. (Hons') $1^{\text {st }}$ class $1^{\text {st }}$ merit position out of 40 successful students from the authority of Islamic University, Bangladesh.

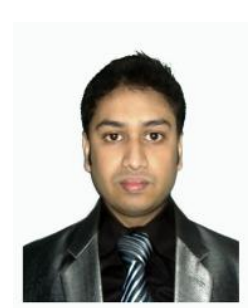

Nabil Hossain Bhuiyan received his B.Sc. (Hons') degree from the dept. of Applied Physics, Electronics and Communication Engineering of Islamic University, Kushtia-7003, Bangladesh in 2014 Currently he is a M.Sc. student in the same department. His current interest includes embedded electronics system design and development, robotics, MATLAB, processing and android based system development and 
communication engineering. He has been certified from number of national robotics and electronics exhibitions.

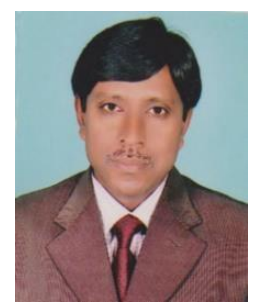

Dr. Md. Shahjahan Ali received his B.Sc (Hons) and M.Sc in 1988 1nd 1989 respectively in Applied Physics and Electronics from Rajshahi University, Bangladesh. He received Ph.D in engineering and technology from Dhaka University in 2011. He is currently a Professor in the Department of Applied Physics, Electronics \& Communication Engineering, Faculty of Applied Science \& Technology, Islamic University, Kushtia-7003, Bangladesh. His research interest includes modelling and optimization of wireless network and application of remote sensing technology.

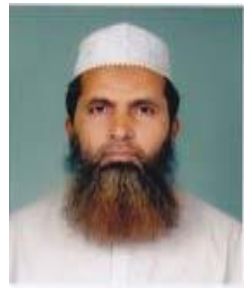

M. K. Rahman was born on July 1, 1971 in Madaripur, Bangladesh. He received the M.Sc. degree in Applied Physics, Electronics \& Communication Engineering from University of Dhaka, Bangladesh in 1992. He is currently a Professor in the Department of Applied Physics, Electronics \& Communication Engineering, Faculty of Applied Science \& Technology, Islamic University, Kushtia-7003, Bangladesh. His interest is in Optoelectronics and Wireless Communication. His work has produced nearly 20 national and international papers.

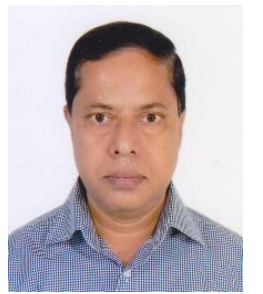

Himangshu Kumar Ghosh has been received the B.Sc. (Hons) and M.Sc. degree in Applied Physics \& Electronics from University of Rajshahi, Rajshahi6205, Bangladesh in 1985 and 1986 respectively. Currently, he is working as Chief Scientific Officer and Director at the Institute of Electronics, Atomic Energy Research Establishment (AERE), Bangladesh Atomic Energy Commission (BAEC), Savar, Dhaka-1349, Bangladesh. His current research interests are nuclear instrumentation, radiation effects on semiconductor \& electronic devices, solar cell, intelligent systems design etc.

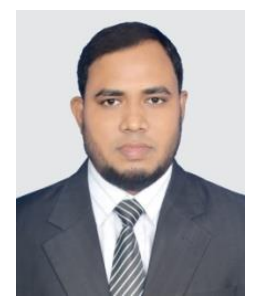

Md. Khalid Hossain has been received the B.Sc. (Hons) and M.Sc. degree in Applied Physics, Electronics \& Communication Engineering of Islamic University, Kushtia-7003, Bangladesh in 2008 and 2009 respectively. Currently he is working as a Scientific Officer in the Institute of Electronics, Atomic Energy Research Establishment (AERE), Bangladesh Atomic Energy Commission (BAEC), Savar, Dhaka-1349, Bangladesh. His current interest is advanced materials science, functional materials, photovoltaic devices, thin film, Micro/Nano fabrication, biosensor, intelligent systems design etc. He is the author/co-author of more than 20 international papers.
How to cite this paper: T. Saha, M. K. H. Jewel, M. N. Mostakim, N. H. Bhuiyan, M. S. Ali, M. K. Rahman, H. K. Ghosh, Md. Khalid Hossain,"Construction and Development of an Automated Greenhouse System Using Arduino Uno", International Journal of Information Engineering and Electronic Business(IJIEEB), Vol.9, No.3, pp.1-8, 2017. DOI: 10.5815/ijieeb.2017.03.01 